Revisão Bibliográfica 




http://revistarebram.com/index.php/revistauniara

\title{
Probióticos E PREBIótios Na PREVEnÇão e TRATAMENTOS de dOENÇAS
}

\author{
Amélia Aparecida Rocca Pereira*; Ana Paula Iani Lusne**. \\ ${ }^{*}$ Graduação de farmácia pela Universidade de Araraquara- UNIARA \\ ${ }^{*}$ Graduação de farmácia pela Universidade de Araraquara- UNIARA \\ *Autor para correspondência e-mail: ameliarocca@hotmail.com
}

\section{Palavras-Chave}

\section{Probióticos}

Prebióticos

Simbióticos

\section{KEYWORDS}

Probiotics

Prebiotics

Symbiotics

\section{RESUMO}

Probióticos são microrganismos vivos que promovem o equilíbrio da microbiota intestinal, deve sobreviver às condições ácidas do estômago e da bile, ser capaz de aderir à mucosa intestinal e colonizá-la mesmo que temporariamente. Os prebióticos são fibras solúveis e fermentáveis, carboidratos não digeríveis, portanto não absorvidos pelo organismo, que contribuem para o crescimento de bactérias desejáveis no cólon. Os simbióticos são resultantes da combinação dos probióticos e prebióticos sendo que seus efeitos podem ser adicionados ou sinérgicos. O presente trabalho teve por objetivo analisar a importância do uso de probióticos e prebióticos para uma melhor qualidade de vida, ressaltando sua importância na prevenção e tratamento de doenças. Dessa forma pode-se concluir que os probióticos e prebióticos apresentam inúmeros benefícios ao organismo associados a uma dieta saudável.

\begin{abstract}
Probiotics AND PREBIOTICS IN THE PREVENTION AND TREATMENT OF DiseASES

Probiotics are live microorganisms that promote the balance of the intestinal microbiota, must survive the acidic conditions of the stomach and bile, be able to adhere to the intestinal mucosa and colonize it even temporarily. Prebiotics are soluble and fermentable fibers, non-digestible carbohydrates, therefore not absorbed by the body, which contribute to the growth of desirable bacteria in the colon. Symbiotics are the result of the combination of probiotics and prebiotics and their effects can be added or synergistic. The present study aimed to analyze the importance of the use of probiotics and prebiotics for a better quality of life, emphasizing its importance in the prevention and treatment of diseases. Thus, it can be concluded that probiotics and prebiotics have numerous benefits to the body associated with a healthy diet.
\end{abstract}




\section{INTRODUÇÃO}

Cada vez mais as pessoas se preocupam com a qualidade de vida e bem estar, cuidando se sua alimentação. Assim vem aumentando a procura por alimentos que tragam benefícios à saúde. Neste contexto, aparecem os alimentos funcionais, onde os probióticos e prebioticos se destacam (WENDLING; WESCHNFELDER, 2013).

Os probióticos e prebióticos são alimentos considerados funcionais, ou seja, são alimentos que produzem efeitos benéficos à saúde (MACEDO et al., 2008).

Definem-se os probióticos como microrganismos vivos que, administrados em quantidades adequadas, promovem o equilíbrio da microbiota intestinal. Um microrganismo probiótico deve, necessariamente, sobreviver às condições ácidas do estômago e da bile, ser capaz de aderir à mucosa intestinal e de colonizar o intestino, mesmo que temporariamente (MELLO et al., 2013).

Os prebióticos são ingredientes nutricionais não digeríveis que estimulam seletivamente o crescimento e atividade de uma ou mais bactérias do cólon, melhorando a saúde de seu hospedeiro. Dessa maneira, os prebiótiocos agem intimamente relacionados aos probióticos, constituindo o alimento das bactérias probióticas (VARAVALLO et al., 2008).

Um produto referido como simbiótico é aquele no qual um probiótico e um prebiótico estão combinados. A interação entre eles, pode ser favorecida por uma adaptação do probiótico ao substrato prebiótico, realizada previamente ao seu consumo (SAAD, 2006).

O efeito simbiótico pode ser direcionado às diferentes regiões "alvo" do TGI, os intestinos delgado e grosso. O consumo de probióticos e de prebióticos selecionados apropriadamente pode aumentar os efeitos benéficos de cada um deles, uma vez que o estímulo de cepas probióticas conhecidas leva à escolha dos pares simbióticos substrato microrganismo ideais (SAAD, 2006).

Uma microbiota intestinal saudável e equilibrada resulta em um desempenho normal das funções fisiológicas do hospedeiro. Este resultado é de suma importância atualmente, tendo em vista o crescente número de indivíduos que se preocupam em melhorar seus hábitos alimentares, assim como os que necessitam de cuidados clínicos nutricionais. Logo, é necessário que, profissionais da saúde tenham o conhecimento dos efeitos benéficos dos alimentos funcionais e da aplicação destes na prática alimentar (SAAD, 2006).

O trato gastrintestinal humano é um microecossistema cinético que possibilita o desempenho normal das funções fisiológicas do hospedeiro, a menos que microrganismos prejudiciais e potencialmente patogênicos dominem. Manter um equilíbrio apropriado da microbiota pode ser assegurado por uma suplementação sistemática da dieta com probióticos e prebióticos (SAAD, 2006).

\section{Metodologia}

O presente estudo foi realizado a partir de uma revisão de literatura, disponível acerca da disbiose intestinal, relacionando-a com a microbiota intestinal e o uso de alimentos funcionais, probióticos e prebióticos no seu tratamento. Para isso, foram utilizados artigos científicos publicados em revistas, jornais, livros e periódicos, e o período de consulta foi de 2000 a 2017. A pesquisa de artigos foi feitas nas bases de dados Google acadêmico e Scielo, usando os termos: prebióticos, probióticos e microbiota intestinal.

\section{Os PROBIóticos}

Alimento funcional é todo alimento que oferece um efeito benéfico, além do valor nutritivo inerente à sua composição química podendo contribuir na prevenção e tratamento de doenças (MACEDO et al., 2008). 
Os probióticos são suplementos alimentares à base de microrganismos vivos capazes de colonizar, estabelecer-se e multiplicar-se no intestino e promover o equilíbrio da microbiota com benefícios para o hospedeiro. Estes benefícios são decorrentes da inibição da proliferação de agentes prejudiciais ao epitélio de revestimento da mucosa intestinal (MELLO et al., 2013).

Alguns critérios são utilizados para definição de um microrganismo como probiótico: - origem humana; não patogênico; resistência a processamento; estabilidade à secreção ácida e biliar; adesão à célula epitelial; capacidade de persistir no trato gastrintestinal; capacidade de influenciar atividade metabólica local (MORAES; JACOB, 2006).

Para garantir um efeito contínuo no organismo humano, os probióticos devem ser ingeridos diariamente. Alterações favoráveis na composição da microbiota intestinal, capazes de garantir a manutenção das concentrações ativas fisiologicamente (quantidade intestinal de $10^{6}$ a $10^{7} \mathrm{UFC}^{-1}$ ) in vivo, foram observadas com doses de $100 \mathrm{~g}$ de produto alimentício contendo $10^{8}$ a $10^{9}$ unidades formadoras de

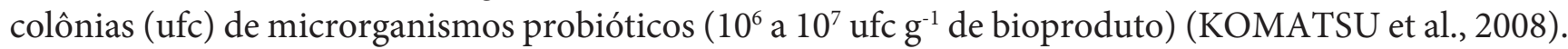

A legislação brasileira recomenda uma população mínima de probióticos de $10^{8}$ a $10^{9}$ UFC em uma porção diária de alimento para que o mesmo possa exercer efeitos benéficos à saúde (BRASIL, 2008).

As bactérias probióticas só apresentam efeitos biológicos no ambiente intestinal se atingirem um número mínimo. Por exemplo, o número de L. rhamnosus para reduzir significativamente a ocorrência da chamada diarreia dos viajantes é de $10^{9} \mathrm{UFC} / \mathrm{g}$. Assim, considerando um consumo de produtos lácteos de $100 \mathrm{~g}$, estes devem conter pelo menos $10^{7} \mathrm{UFC} / \mathrm{g}$ de bactérias probióticas viáveis no momento da compra do produto. Esse é o número recomendado por diversos autores (STURMER et al., 2012).

Não foi ainda comprovado o mecanismo de ação desses probióticos, mas há fortes evidências de que eles podem, inibir a proliferação de organismos patogênicos, ou porque competem por nutrientes ou porque produzem compostos como citocinas e ácido butírico. Com a redução do pH no meio, há estímulo para crescimento da microflora produtora de ácido lático. Outro mecanismo proposto seria o deslocamento dos microrganismos patogênicos dos sítios de ligação ou receptores celulares (SETTA, 2010).

A redução das enzimas $\beta$-glicuronidase e nitroredutase, produzidas por bactérias patogênicas, leva à hidrólise de compostos carcinogênicos, reduzindo as substâncias nocivas e, assim, diminuindo o risco de neoplasias, com isso reduz-se o número de bactérias envolvidas na pró-carcinogênese e mutagênese (STURMER et al., 2012).

\section{Principais BACTÉrias EMPREgAdAS NOS ALIMENTOS FUNCIONAIS PROBIóticos}

Dentre os microrganismos probióticos mais utilizados, destacam-se várias cepas de lactobacilos e bifidobactérias. De modo geral, lactobacilos podem colaborar na digestão da lactose em indivíduos com intolerância a esse dissacarídeo, reduzir a constipação e a diarreia infantil, ajudar na resistência a infecções por Salmonela, prevenir a "diarreia do viajante” e aliviar a síndrome do intestino irritável. Bifidobactérias são conhecidas por estimularem o sistema imunológico, produzirem vitamina $B$, aumento da absorção de minerais e produção de vitaminas, inibirem a multiplicação de patógenos através da produção de ácidos acético e lático, de bacteriocinas e de outros compostos antimicrobianos; reduzirem a concentração de amônia e colesterol no sangue, e ajudarem a restabelecer a microbiota normal após tratamento com antibióticos. Assim sendo, esses microrganismos são comumente utilizados em intervenções dietéticas que visam à melhoria da saúde, reduz atividade ulcerativa de Helicobacter pylori, controle da colite induzida por rotavírus e por Clostridium difficile, prevenção de infecções urogenitais, além de efeitos inibitórios sobre a mutagenicidade (KOMATSU et al., 2008).

Dentre as bactérias pertencentes ao gênero Bifidobacterium, destacam-se a B. bifidum, B. brevis, B. 
infantis, B. lactis, B. animalis, B. longum e B. thermophilum. Dentre as bactérias láticas pertencentes ao gênero Lactobacillus, destacam-se a L. acidophilus, L. helveticus, L. casei - subsp. paracasei e subsp. tolerans, L. paracasei, L. fermentum, L. reuteri, L. johnsonii, L. plantarum, L. rhamnosus e L. Salivarius (FOOD INGREDIENTS BRASIL, 2011).

\section{EFEITOS ATRIbuídos AOS PROBióticos}

As formas mais comuns de apresentação dos probióticos são os produtos lácteos, como, por exemplo, iogurtes, leites fermentados e queijos. No entanto, também existem no mercado cápsulas e sachês contendo bactérias na forma liofilizada (SAAD et al., 2011).

$\mathrm{O}$ iogurte, um dos mais antigos alimentos funcionais consumidos pelos humanos, apresenta algumas propriedades nutricionais de alto valor:

A) por conter baixo teor de lactose facilita a assimilação do iogurte em indivíduos com intolerância à lactose;

B) proteólise e digestão: as proteínas do leite, que têm um alto valor biológico, são parcialmente prédigeridas por ação de enzimas proteolíticas das bactérias lácticas, o que permite uma melhor digestão;

C) vitaminas: as vitaminas do leite ajudam o crescimento das bactérias lácticas que, por sua vez, produzem outras vitaminas, aumentando assim a variedade de vitaminas presentes no iogurte;

D) Minerais: o iogurte apresenta uma ampla variedade de minerais provenientes do leite, destacandose com maior importância o cálcio, que neste produto apresenta-se com elevada biodisponibilidade (VARAVALLO et al., 2008).

Entende-se por iogurte o produto cuja fermentação se realiza com cultivos protossibióticos de Streptococcus salivarius subsp. Thermophilus e Lactobacillus delbrueckii subsp bulgaricus, que podem ser acompanhados, de forma complementar, por outras bactérias acido-láticas, as quais, por sua atividade, contribuem para determinação das características do produto final (CUPPARI, 2014).

Empresas de laticínios têm adotado a prática de inserir as bactérias probióticas em leites fermentados e outros produtos. Fatores importantes como a interação entre as espécies, a acidez do iogurte, a oxigenação, as condições de fermentação, o pH do produto, as práticas de inoculação, a temperatura e também as condições de estocagem e armazenamento influenciam diretamente na sobrevivência desta microbiota nos alimentos lácteos fermentados (HUNGRIA; LONGO, 2009). A incorporação de Lactobacillus acidophilus e Bifidobacterium em bebidas fermentadas pode resultar em um produto lácteo com extraordinário valor terapêutico e eficaz redução calórica (THAMER; PENNA, 2005).

Quanto maior o teor de soro, menor a acidez titulável e menor o teor de proteínas (THAMER; PENNA, 2006).

O desenvolvimento de uma bebida láctea fermentada com culturas probióticas e acrescida de prebióticos geram novos recursos e, principalmente, melhoram o valor nutritivo do produto (THAMER; PENNA, 2006).

\section{Probióticos E SAÚDE GÁSTRICA}

Normalmente, poucas bactérias permanecem no estômago ou intestino delgado após uma refeição por causa das ações do ácido clorídrico, pepsina e bile, que funcionam como agente germicida. No entanto, uma diminuição das secreções gástricas pode permitir que os micróbios sobrevivam por mais tempo. Em consequência, pode aumentar o risco de inflamações da mucosa gástrica (gastrite), o risco de super crescimento bacteriano no intestino delgado ou o número de micróbios que chegam ao cólon. A Helicobacter pylori é uma bactéria com tolerância ao ácido que provoca infecção no estômago, podendo 
causar gastrite e úlcera, além de ser um fator de risco para o desenvolvimento de câncer gástrico (MAHAN; STUMP, 2010).

Como os probióticos se aderem à mucosa e produzem substâncias bactericidas eles impedem a colonização de Helicobacter pylori nas células epiteliais. Também atuam no sistema imunológico que auxilia na redução da inflamação das células estomacais (WENDLING; WESCHNFELDER, 2013).

Diversos estudos demonstraram o efeito benéfico de L.johnsonni La-1 em relação à gastrite causada por Helicobacter pylori, suprimindo a atividade da urease do patógeno em voluntários assintomáticos. Também foram observados efeitos positivos em relação à redução dos sintomas da infecção gástrica e colonização por H.pylori, quando as cepas probióticas L.acidophilus La5 e Bb-12 foram avaliados em pacientes com gastrite (MARTINEZ et al., 2015).

\section{Probióticos e Saúde intestinal}

A maior parte dos estudos sobre a utilização de probióticos está focada no TGI. Neste local, acreditase que os probióticos sejam capazes de competir com microrganismos patogênicos por sítios de adesão e nutrientes, além de produzirem diferentes compostos antimicrobianos, um processo denominado “resistência à colonização" ou "exclusão competitiva” (MARTINEZ et al., 2015).

\section{OS PREBIóticos}

Um prebiótico, ingrediente alimentício não digerível, afeta beneficamente quem o ingere pela estimulação seletiva do crescimento e/ou da atividade de uma ou de número limitado de espécies de bactérias no cólon. O conceito é bastante semelhante ao da fibra alimentar, a não ser pelo aspecto da seletividade em relação às espécies bacterianas. Essa seletividade já foi observada para as bifidobactérias, as quais podem ser estimuladas pela ingestão de substâncias como frutooligossacarídeos, inulina, lactulose, amido resistente, oligossacarídeos transgalactosilados e oligossacarídeos da soja (BALLUS, 2010).

Dentre os principais prebióticos que têm recebido maior atenção, destacam-se a inulina e os oligossacarídeos, especialmente os frutooligossacarídeos (FOS). Os oligossacarídeos são açúcares encontrados como componentes naturais em muitos alimentos como frutas, vegetais, leite e mel. O mel é um alimento funcional que exerce a atividade prebiótica e tem como efeito, a regulação do trânsito intestinal, regulação da pressão arterial, redução do risco de câncer e dos níveis de colesterol (MACEDO et al., 2008).

Os fruto-oligossacarídeos (FOS) ou oligofrutoses são carboidratos complexos de configuração molecular que os tornam resistentes à ação hidrolítica da enzima salivar e intestinal, chegando intactos ao cólon. São formados a partir da hidrólise da inulina, que tem diversas funções no organismo, como alteração do trânsito intestinal, redução do colesterol plasmático e da hipertrigliceridemia, melhoram a biodisponibilidade de minerais e contribuem para o aumento da concentração das Bifidobacterium no cólon. São moléculas presentes na cebola, raízes de almeirão, beterraba, chicória, alho, lecitinas, alcachofra, cereais, aspargos, banana, trigo e tomate (STURMER et al., 2012).

Os critérios para que um ingrediente dietético seja caracterizado como prebiótico são:

1) A fermentabilidade deve ser demonstrada em experimentos in vitro que estimula, por exemplo, as condições fisiológicas encontradas no TGI. Substratos promissores devem ser avaliados em estudos clínicos, randomizados e controlados por placebo, no sentido de comprovar os resultados alcançados nos estudos in vitro;

2) A principal característica de um prebiótico é ser um substrato seletivo para uma ou mais bactérias comensais benéficas do TGI, que são estimuladas a se multiplicarem e/ou são metabolicamente ativadas, o que pode alterar, consequentemente, a microbiota colônica do hospedeiro para uma composição mais 
saudável (MARTINEZ et al., 2015).

Para garantir um efeito contínuo, assim como os probióticos, os prebióticos devem ser consumidos diariamente. Alterações favoráveis na microbiota intestinal foram observadas com doses de 4 a $20 \mathrm{~g} / \mathrm{dia}$ de inulina e/ou FOS (MARTINEZ et al., 2015).

A dose diária de prebióticos recomendada pela legislação brasileira é de $3 \mathrm{~g}$ para alimentos sólidos e 1,5g para alimentos líquidos (BRASIL, 2008).

\section{EFeitos Atribuídos aos Prebióticos}

Alguns efeitos atribuídos aos prebióticos são a modulação de funções fisiológicas chaves, como a absorção de cálcio e, possivelmente, o metabolismo lipídico, a modulação da composição da microbiota intestinal, a qual exerce um papel primordial na fisiologia gastrintestinal, e a redução do risco de câncer de cólon (SAAD, 2006).

A estrutura molecular dos prebióticos pode determinar os efeitos fisiológicos e quais espécies de microrganismos serão capazes de utilizá-los como fonte de carbono e energia. As bifidobactérias são os microrganismos mais envolvidos nessa resposta, os mecanismos pelos quais os probióticos promovem a proliferação desses microrganismos ainda não estão esclarecidos, contudo, diversas hipóteses podem ser citadas:

1) as bifidobactérias podem utilizar uma ampla variedade de oligossacarídeos e carboidratos complexos como fontes de carbono e energia;

2) na presença de oligossacarídeos não digeríveis, as bifidobactérias exibem taxas de multiplicação superior aquelas observadas em bactérias putrefativas ou potencialmente patogênicas no intestino;

3)As bifidobactérias se multiplicam mais eficientemente sendo tolerantes aos ácidos graxos de cadeia curta e a acidificação do ambiente intestinal, geralmente não hidrolisam extracelularmente os oligossacarídeos não digeríveis, uma vez que possuem permeasses que internalizam esses substratos antes de hidrolisá-los e metabolizá-los, minimizando assim, a liberação de açucares simples que podem ser consumidos por outras bactérias intestinais (MARTINEZ et al., 2015).

\section{FERMENTAÇÃo baCteriana E EFEITOS FiSIOLÓgicos}

A ação bacteriana é mais intensa no intestino grosso. Após uma refeição, as fibras dietéticas, amidos resistentes e muco descamado pelo intestino são fermentados no cólon. As bactérias do cólon contribuem para a formação de gases (hidrogênio, dióxido de enxofre, nitrogênio) e ácido graxos de cadeia curta (AGCC). As bactérias do cólon continuam a digestão de alguns materiais que tenham resistido a ação digestiva prévia. Durante o processo, vários nutrientes são formados por síntese bacteriana. Esses nutrientes são utilizados em graus variados pelas células da mucosa GI, mas geralmente contribuem pouco para as necessidades energéticas de um hospedeiro humano (MAHAN; STUMP, 2010).

A presença do alimento no intestino é fator preponderante para manutenção de uma massa celular funcional. A maior parte dos oligossacarídeos e polissacarídeos presentes na dieta é quantitativamente hidrolisada nas regiões superiores do trato digestório. Os monossacarídeos resultantes são absorvidos e transportados pela circulação portal para o fígado e, para circulação sistêmica. Esses carboidratos servem como substratos as principais vias metabólicas e liberação de diversos hormônios gastrintestinais. Nesse processo metabólico conhecido como fermentação, são produzidos gases $\left(\mathrm{H}_{2} \mathrm{CO}_{2} \mathrm{CH}_{4}\right.$, ácidos orgânicos (como fumarato, lactato, succinato) e AGCCs, como acetato, propionato e butirato, que produzem variados efeitos para a saúde do hospedeiro. O butirato, por sua vez, é reconhecido como a principal fonte de energia para a mucosa colônica, afetando a proliferação, diferenciação e apoptose dos colonócitos (CUPPARI, 2014). 


\section{AS FIBRAS E OS PREBIÓTICOS}

A fibra alimentar é a parte comestível de plantas ou carboidratos análogos que são resistentes à digestão e a absorção no intestino delgado de humanos com fermentação completa ou parcial no intestino grosso. A fibra alimentar inclui polissacarídeos, oligossacarídeos, lignina e substâncias associadas de plantas. Conforme sua solubilidade no trato digestório, a fibra alimentar pode ser classificada em solúvel e insolúvel. Fazem parte das fibras solúveis, uma boa parte dos oligossacarídeos, incluindo a polidextrose, a pectinas, a hemicelulose, os betaglicanos, as gomas e os frutanos (inulina e FOS). Dentro da classificação das fibras insolúveis, estão compreendidas a lignina, a celulose e a hemicelulose. $\mathrm{O}$ alvo de ação da fibra alimentar é o trato digestório, servindo de substrato para a microbiota intestinal, promovendo laxação normal e modulando a velocidade de digestão e absorção dos nutrientes. Nesse aspecto, suas características físico-químicas, como solubilidade, viscosidade, capacidade de retenção de água, efeito da massa/volume, ligação com ácidos biliares e suscetibilidade à fermentação, interferem sobremaneira em sua função no trato digestório. Essas características variam em função da estrutura química dos componentes que fazem parte da fibra alimentar (CUPPARI, 2014).

Os efeitos do uso das fibras são a redução dos níveis de colesterol sanguíneo e diminuição dos riscos de desenvolvimento de câncer, decorrentes de três fatores: capacidade de retenção de substâncias tóxicas ingeridas ou produzidas no trato gastrointestinal durante processos digestivos; redução do tempo do trânsito intestinal, promovendo uma rápida eliminação do bolo fecal, com redução do tempo de contato do tecido intestinal com substâncias mutagênicas e carcinogênicas e formação de substâncias protetoras pela fermentação bacteriana dos compostos de alimentação.

Uma dieta pobre em fibras, baseada principalmente em carnes, gorduras e carboidratos facilmente digeríveis resulta em maior proporção de bactérias "putrefativas" ou potencialmente prejudiciais, como as Pseudomonas, Clostridium, E. coli e Proteus (MAHAN; STUMP, 2010).

\section{Os Simbióticos}

Simbióticos são produtos que contém uma combinação de probióticos e prebióticos. Esta associação beneficia o hospedeiro, pois há introdução direta de bactérias viáveis no organismo pela ingestão das culturas probióticas, e promoção do crescimento de bactérias benéficas já existentes no cólon por meio da fermentação seletiva do prebiótico (PIMENTEL et al., 2011).

Há dois tipos de abordagens com relação aos simbióticos:

1) Complementar, em que o probiótico é escolhido com base nos efeitos benéficos desejados sobre o hospedeiro, e o prebiótico é selecionado de forma independente, com objetivo de aumentar seletivamente as concentrações de componentes benéficos da microbiota intestinal;

2) Sinérgica, o prebiótico é escolhido especificamente para estimular a multiplicação e a atividade do microrganismo probiótico selecionado. Nesse caso, o prebiótico é selecionado por ter uma maior afinidade com o probiótico e por melhorar a sobrevivência e a multiplicação desse microrganismo no hospedeiro (MARTINEZ et al., 2015).

\section{USo CLÍ́NICo}

\section{CONSTIPAÇÃo INTESTINAL}

Muitos fatores contribuem para o desenvolvimento de constipação intestinal, particularmente no envelhecimento, como mudanças na dieta e na ingestão de fluidos, diminuição na ingestão de produtos 
contendo fibras, ingestão de medicamentos, diminuição da motilidade intestinal e inatividade física. Diversos estudos sugerem que a fermentação de carboidratos estimula a motilidade do cólon (SAAD, 2006).

O tratamento nutricional para constipação é o consumo de quantidades adequadas tanto de fibras alimentares solúveis como insolúveis. As fibras aumentam o conteúdo de líquido fecal, massa microbiana, peso das fezes e frequência e velocidade do trânsito colônico. As fibras podem ser fornecidas sob a forma de grãos integrais, frutas, vegetais, legumes, sementes e castanhas. Estes alimentos também são ricos em nutrientes, fitoquímicos saudáveis e amidos resistentes e podem atuar como prebióticos para manter a microflora colônica desejável (MAHAN; STUMP, 2010).

\section{INTOLERÂNCIA À LACTOSE}

Se manifesta devido à ausência da enzima $\beta$-galactosidase no intestino que impossibilita a degradação da lactose presente em alimentos como o leite. Para as pessoas intolerantes a lactose os leites fermentados são mais bem aceitos, pois a lactose presente no leite é reduzida durante a fermentação pelos lactobacilos e pelas bifidobactérias (WENDLING; WESCHNFELDER, 2013).

Bactérias como Lactobacillus acidophilus encontradas em leites fermentados, também produzem essa enzima, o que possibilita que as moléculas de lactose presente no leite sejam clivadas em moléculas menores, facilitando sua digestão e beneficiando assim as pessoas com intolerância à lactose (SAAD; THAMER; PENNA, 2006).

A maioria dos indivíduos com má digestão de lactose pode consumir um pouco de lactose $(6$ a $12 \mathrm{~g} /$ dia) sem sintomas importantes, especialmente quando ingerida nas refeições ou sob a forma de queijos ou laticínios cultivados. A exposição incremental ou contínua a quantidades crescentes de açucares fermentáveis pode levar à melhora da tolerância, não como consequência de aumento de produção de lactase, mas talvez por alteração da flora colônica. A tolerância ao iogurte pode resultar da galactosidase microbiana na cultura de bactérias que facilita a digestão da lactose no intestino. A presença de galactosidase depende da marca e método de processamento. Devido a esta enzima microbiana ser sensível ao congelamento, o "frozen iogurt" pode não ser tão bem tolerado, mas a adição de probióticos pode alterar essa condição (MAHAN; STUMP, 2010).

No caso dos iogurtes, a lactose presente nesse alimento é mais tolerada e bem digerida que a presente no leite, por causa do retardo do esvaziamento gástrico, do tempo de trânsito intestinal e da capacidade de seus microrganismos (em especial, Lactobacillus bulgaricus) em hidrolisar a lactose (CUPPARI, 2014).

\section{IMUNIDADE}

Quanto ao efeito dos probióticos na função imunológica, há evidências de que podem estimular tanto a resposta específica quanto a inespecífica. Esses efeitos são mediados pelo aumento dos níveis de citocinas, pela ativação de macrófagos e pelo aumento da concentração de imunoglobulinas. Pode também haver um sinergismo do efeito na função imunológica quando, por exemplo, os lactobacilos são consumidos junto com as bifidobactérias (CUPPARI, 2014).

A membrana que reveste o intestino é protegida por um sistema imunológico adaptativo. Para que os probióticos consigam influenciar na resposta imunológica, eles precisam ativar este tecido linfóide, que são as placas de Peyer e as células intestinais. Essas duas estimulam a comunicação dos linfócitos B e T com outros tecidos e são produtoras de imunoglobulina A (IgA) (COPPOLA; TURNES, 2004).

Merece destaque o fato de que esses efeitos positivos dos probióticos sobre o sistema imunológico ocorrem sem o desencadeamento de uma resposta inflamatória prejudicial. Entretanto, nem todas as cepas de bactérias láticas são igualmente efetivas. A resposta imune pode ser aumentada, quando um ou 
mais probióticos são consumidos concomitantemente atuando sinergicamente, como parece ser o caso dos Lactobacillus administrados em conjunto com Bifidobacterium (SAAD, 2006).

A introdução oral de Lactobacillus casei e Lactobacillus bulgaricus ativa a produção de macrófagos, e a administração de L. casei e Lactobacillus acidophilus ativa a fagocitose. É interessante notar, portanto, que as bactérias probióticas modulam a fagocitose de forma diferente em indivíduos saudáveis e alérgicos: em pessoas saudáveis, houve um efeito imunoestimulante, enquanto em alérgicas, foi detectada regulação negativa da resposta inflamatória (ISOLAURI et al., 2001).

\section{Diarreia}

O benefício dos probióticos frente à diarreia, apresentado em diferentes estudos, está relacionado com o seu mecanismo de ação, que envolve a produção de substâncias como o ácido lático e o acético, o peróxido de hidrogênio e o diacetil, que inibem a atividade de outros micro-organismos patogênicos, apresentando em alguns casos ação bactericida (BALLUS et al., 2010).

Os efeitos dos probióticos na diarreia aguda incluem a produção de substâncias antibacterianas (bacteriocinas, lactocinas, bifidinas), produção de ácidos graxos que acidificam o lúmen intestinal, inibindo bactérias e mantendo o bom funcionamento da mucosa intestinal, diminuição da permeabilidade intestinal, ação competitiva e imunomodulação com aumento de IgA, regulação de citocinas e da resposta imune. Segundo alguns estudos, a diarreia provocada por antibioticoterapia pode ser prevenida com a ingestão de probióticos contendo Bifidobacterium longum e, ainda, em associação a culturas probióticas de Bifidobacterium longum e Saccharomyces boulardi (FOOD INGREDIENTS BRASIL, 2011).

Há estudos, as quais verificou-se que uma bebida contendo L. casei DN-114 001, L.bulgaricus e Streptococcus thermophilus reduziu o risco da diarreia associada ao uso de antibióticos e da diarreia associada a C. difficile entre idosos em $22 \%$ e $17 \%$, respectivamente. Diversos estudos também demonstraram que as cepas probióticas Lactobacillus rhamnosus GG, Lactobacillus reuteri, Lactobacillus casei Shirota e Bifidobacterium animalis $B b-12$ foram capazes de reduzir a duração da diarreia por rotavírus em aproximadamente um dia. Probióticos também podem ser úteis na prevenção da diarreia do viajante, uma condição comumente observada em pessoas que se dirigem a países econômicos e socialmente menos desenvolvidos e que apresentam climas mais quentes (MARTINEZ et al., 2015).

O uso de quantidades modestas de alimentos ou suplementos alimentares contendo componentes prebióticos, como pectina, oligossacarídeos, frutose, inulina, flocos de banana e chicória, podem realmente auxiliar o controle e tratamento da diarreia. Os prebióticos ajudam por favorecerem a manutenção de lactobacilos "amigos" e micróbios bifidus e poderem prevenir o crescimento excessivo de organismos potencialmente patogênicos. Substâncias fibrosas e vários tipos de alimentos prebióticos também tendem a lentificar o esvaziamento gástrico, moderar o trânsito GI e reter água (MAHAN; STUMP, 2010).

\section{CÂNCER dE CÓLON}

Os prebióticos tem sido estudados quanto ao seu efeito protetor no desenvolvimento do câncer colorretal, destacando-se os FOS e a inulina. A fermentação dos prebióticos no cólon leva a formação de ácidos graxos de cadeia curta, dentre os quais se destaca o butirato, que é uma substância capaz de induzir a diferenciação de células tumorais colorretais (MARTINEZ et al., 2015).

O consumo de produtos laticínios fermentados pode oferecer algum efeito protetor contra adenomas ou carcinomas do cólon. Pressupõe-se que microrganismos selecionados seriam capazes de proteger o hospedeiro contra atividades carcinogênicas, através de três mecanismos:

1. Os probióticos seriam capazes de inibir as bactérias responsáveis por converter substâncias pré- 
carcinogênicas (como os hidrocarbonetos policíclicos aromáticos e nitrosaminas) em carcinogênicas;

2. Estudos em animais de laboratório têm demonstrado que alguns probióticos inibem diretamente a formação de células tumorais;

3. Algumas bactérias da flora intestinal têm mostrado capacidade de ligação e/ou inativação carcinogênica (DENIPOTE; TRINDADE; BURINI, 2010).

O uso de prebióticos e probióticos altera a microflora colônica, induz a glutationa transferase, aumenta o conteúdo de butirato das fezes, reduz componentes tóxicos e genotóxicos e em modelos animais reduz o desenvolvimento de algumas lesões pré-cancerosas (MAHAN; STUMP, 2010).

\section{Alergias}

Tanto Lactobacillus como Bifidobactérias são capazes de promover lise de proteínas com potencial alergênico no trato gastrintestinal. Esse processo pode contribuir para a redução da alergenicidade das proteínas, minimizando o risco de alergia alimentar (NOGUEIRA; GONÇALVES 2011).

Diversos mecanismos são propostos para explicar a interação de probióticos e o sistema imune, destacam-se: o estímulo da secreção de IgA em superfícies mucosas, indução da produção de citocinas pró-inflamatórias ou regulatórias, modulação da maturação diferencial de células dendríticas e, ainda, interação com o sistema imune através de sinalização via Toll-like receptor. Alguns estudos clínicos já demonstraram um efeito benéfico protetor na prevenção de doença atópica em recém-nascidos, cujas mães, durante o período gestacional, tiveram a dieta suplementada com culturas probióticas, como $L$. rhamnosus GG (MARTINEZ et al., 2015).

\section{HiPERCOLESTEROLEMIA E DOENÇAS CARDIOVASCULARES}

Alguns probióticos podem exercer efeitos hipocolesterolêmicos, contribuindo para a diminuição do colesterol sanguíneo de três maneiras distintas: utilizando o colesterol no intestino e reduzindo a sua absorção; aumentando a excreção de sais biliares e produzindo ácidos graxos voláteis no cólon, os quais podem ser absorvidos e interferir no metabolismo dos lipídios no fígado. O efeito hipocolesterolêmico é, provavelmente, exercido pela inibição da enzima 3-hidroxi 3-metilglutaril (HMG) CoA redutase, que é uma enzima taxa-limitante que catalisa o passo principal na biossíntese do colesterol endógeno (FOOD INGREDIENTS BRASIL, 2011).

As doenças cardiovasculares constituem atualmente, a principal causa de mortes no mundo e sua incidência vem aumentando nos últimos anos. Pesquisadores avaliaram um grupo de pessoas com hipercolesterolemia e verificaram que, após seis semanas de consumo de iogurte contendo as bactérias láticas Lactobacillus acidophilus e Bifidobacterium lactis, as taxas de colesterol sanguineo foram significativamente reduzidas, em comparação ao grupo que fez uso de iogurte tradicional (MARTINEZ et al., 2015).

As fibras solúveis presentes nas pectinas, gomas, mucilagens, polissacarídeos de algas e em algumas hemiceluloses diminuem o LDL. A quantidade de fibras necessária para produzir efeito na diminuição do nível de lipídios varia de acordo com a fonte de alimento, de modo que são necessárias maiores quantidades de legumes do que pectinas ou gomas. Os mecanismos propostos para o efeito hipocolesterolêmico da fibra solúvel são os seguintes: 1) a fibra se liga nos ácidos biliares, que diminuem o colesterol sérico para reestabelecer o pool de ácido biliar; 2) as bactérias no cólon fermentam a fibra para produzir acetato, propionato e butirato, que inibem a síntese de colesterol. As fibras insolúveis, como a celulose e a lignina, não possuem efeito sobre os níveis de colesterol sérico (MAHAN; STUMP, 2010). 


\section{OSTEOPOROSE}

Diversos mecanismos têm sido propostos para explicar o efeito de FOS na absorção e retenção de cálcio. Um deles está relacionado à atuação das bactérias do cólon, as quais são capazes de fermentar os FOS e outros carboidratos não digeríveis, aumentando a produção de ácidos graxos de cadeia curta (como butirato, propionato e acetato), além de outros ácidos orgânicos, como o ácido lático. Essas substâncias são capazes de reduzir o pH, acidificando o conteúdo luminal; assim, nessas condições, compostos insolúveis, como o fosfato de cálcio são dissolvidos no lúmen (cálcio ionizado) e ocorre aumento da sua absorção através da difusão passiva (MARTINEZ et al., 2015).

A inulina apresenta os efeitos mais expressivos em relação ao aumento da biodisponibilidade do cálcio (LAVANDA et al., 2011).

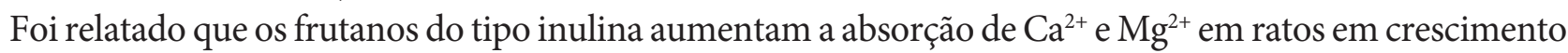
e aumentam o equilíbrio iônico de ferro e $\mathrm{Zn}^{2+}$, sem ter um efeito significativo na biodisponibilidade de $\mathrm{Cu}^{2+}$. Estudos em humanos confirmaram o efeito positivo da inulina e da oligofrutose sobre a absorção e o equilíbrio do cálcio na dieta, mas não do ferro, magnésio ou zinco (ROBERFROID, 2000).

Em relação aos probióticos, acredita-se que seu efeito na biodisponibilidade de minerais esteja relacionado à síntese de poliamidas, que são metabólitos produzidos por diversas cepas microbianas e que podem estimular a multiplicação celular, levando ao aumento da superfície absortiva. Além disso, os probióticos são capazes de produzir vitaminas, as quais são requeridas para a formação da matriz óssea e crescimento do osso (MARTINEZ et al., 2015).

Constatou-se que mulheres menopausadas, que receberam diariamente $10 \mathrm{~g}$ de lactulose apresentaram níveis mais elevados de cálcio absorvido em comparação a seus respectivos controles. Entretanto, estudos adicionais são necessários para que possa ser determinado com exatidão os efeitos e os mecanismos de ação envolvidos na redução do risco da osteoporose através do consumo de probióticos e prebióticos (MARTINEZ et al., 2015).

\section{Doença de Crohn e Colite Ulcerativa}

A doença de Crohn é caracterizada por abcessos e fístulas, fibrose, espessamento da submucosa, estreitamentos de segmentos intestinais e obstrução parcial ou completa do lúmen intestinal. O sangramento é mais comum na colite ulcerativa, sendo o processo da doença mais contínuo. Alimentos probióticos e suplementos podem ajudar a modificar a flora microbiana ou suprimir a resposta inflamatória. Os alimentos prebióticos como oligossacarídeos, fibras fermentáveis e amidos resistentes podem alterar a mistura de microrganismos na flora colônica, favorecendo os lactobacilos e bifidobactérias, suprimindo a microflora patogênica e oportunista e o aumento da produção de AGCCs. A flora alterada de AGCCs produzidos, também podem servir para atenuar o processo inflamatório, especialmente na colite ulcerativa (MAHAN; STUMP, 2010).

\section{SÍNDROME DO CÓLON IRRITável}

Diferentes mecanismos têm sido propostos para explicar o efeito benéfico dos probióticos em pacientes com doenças inflamatórias intestinais, os quais incluem competição por nutrientes e/ou sítios de adesão, produção de substâncias antimicrobianas e/ou de comunicação via célula/célula. Os probióticos podem afetar o sistema imune através da interação de produtos bacterianos, como componentes celulares ou DNA, com células imunes epiteliais e associadas ao intestino. Além disso, alguns estudos também tem demonstrado mudanças no perfil de citocinas produzidas, modulação na função de células dendríticas, aumento da atividade das células NK e indução das células T reguladoras e defensiva (MARTINEZ et 
al., 2015).

\section{CÁRIES, DOENÇAS PERIOdONTAIS E HALITOSE}

A cárie é uma das doenças crônicas mais prevalentes no mundo, de origem bacteriana, apresenta causa multifatorial e é caracterizada pela desmineralização do esmalte dentário (BASTOS et al., 2012). A fim de que probiótico apresente efeito benéfico, limitando ou impedindo o desenvolvimento da cárie, é necessário que o microrganismo seja capaz de aderir a superfície dentária e se integrar ao biofilme bacteriano, local em que deverá competir com as bactérias cariogênicas, prevenido sua multiplicação. Além disso, é necessário que o probiótico, ao metabolizar açucares obtidos a partir da dieta, produza baixos níveis de ácido (BONIFAIT et al., 2009).

Diversos estudos clínicos demonstraram que o consumo regular de iogurte, leite ou queijos contendo culturas probióticas levou a redução no número de estreptococos cariogênicos na saliva e na placa dentária. Porém, para maior eficácia na cavidade oral, fórmulas ou dispositivos de liberação lenta podem ser necessários a fim de que os probióticos permaneçam por mais tempo na cavidade oral. Atualmente, são comercializados probióticos em balas e chicletes que contém o Lactobacillus reuteri (BASTOS et al., 2012).

A doença periodontal é classificada em gengivite e periodontite. A primeira é caracterizada pela inflamação limitada ao tecido gengival, enquanto a periodontite é uma doença progressiva, que destrói os tecidos de suporte dos dentes, incluindo o osso alveolar. Alguns estudos evidenciaram a capacidade de algumas cepas de lactobacilos inibirem a multiplicação de patógenos relacionados ao desenvolvimento da doença periodontal, dentre eles podemos citar: L. reuteri e L. brevis CD2 (MARTINEZ et al., 2015).

O interesse da utilização dos probióticos na doença periodontal se deve aos dois principais mecanismos de ação: um relacionado à colonização bacteriana e outro relacionado à modulação da resposta do hospedeiro. Os probióticos atuam prevenindo a adesão, multiplicação e integração de bactérias patogênicas no biofilme e também inibem o crescimento de alguns patógenos através de determinadas substâncias como o ácido lático, peróxido de hidrogênio e as bacteriocinas. Os efeitos na resposta do hospedeiro são: inibição das colagenases e redução das moléculas associadas à inflamação, indução da expressão das proteínas citoprotetoras nas superfícies das células do hospedeiro, modulação de vias pró-inflamatórias induzidas por patógenos, prevenção da apoptose induzida por citocinas e modulação da resposta imune do hospedeiro (BASTOS et al., 2012).

Outro exemplo da utilização de probióticos na prática odontológica é verificado no tratamento da halitose, uma doença que apresenta diversas causas, incluindo desordens metabólicas, consumo de determinados tipos de alimentos e infecções do trato respiratório. Contudo, a maior parte dos casos da patologia está associado ao desequilíbrio da microbiota comensal presente na cavidade oral. Pesquisas realizadas apresentaram melhora dos níveis de Streptococcus salivarius K12 e redução das populações bacterianas responsáveis pelo mau odor, determinados nas amostras de saliva avaliados (MARTINEZ et al., 2015).

\section{PossíveIS EFEITOS ADVERSOS dOS PROBIÓTICOS E PREBIÓTICOS}

Assim como no caso dos demais tipos de fibra, o consumo de quantidades excessivas de prebióticos pode resultar em diarreia, flatulência, cólicas, inchaço e distensão abdominal, estado este reversível com a interrupção da ingestão. Quanto aos probióticos, estudos clínicos controlados com lactobacilos e bifidobactérias não revelaram efeitos maléficos causados por esses microrganismos (SAAD, 2006).

\section{Conclusão}


Os profissionais da área da saúde, além das terapias medicamentosas devem estar atentos as terapias não medicamentosas, sendo muito importante a orientação à população; mostrando que a suplementação através desses alimentos pode trazer diversos benefícios, prevenindo e tratando doenças, minimizando as complicações relacionadas ao trato gastrointestinal e reduzindo os índices de câncer. Uma microbiota intestinal saudável e equilibrada resulta em um desempenho normal das funções fisiológicas do hospedeiro, o que irá assegurar melhoria na qualidade de vida do indivíduo. Alguns mecanismos para a ocorrência dos efeitos probióticos e prebióticos foram elucidados, entretanto, estudos nesse sentido são cada vez mais intensos. Melhor compreensão sobre a interação entre os compostos vegetais não-digeríveis, seus metabólitos, a microbiota intestinal e o hospedeiro abrirá novas possibilidades de produzir novos ingredientes para produtos alimentícios nutricionalmente otimizados que promovam a saúde do hospedeiro, através de reações microbianas no intestino.

\section{REFERÊNCIAS}

BALLUS, C. A.; KLA JN, V. M.; CUNHA, M. F.; OLIVEIRA, M. L.; FIORENTINO, A. M. Aspectos Científicos e Tecnológicos do Emprego de Culturas Probióticas na Elaboração de Produtos Lácteos Fermentados: revisão. Boletim do Centro de Pesquisa de Processamento de Alimentos, Curitiba, v.28, n. 1, p.85-96, Jan/Jun, 2010.

BASTOS, E. M.; BRITO, F.; SILVA, R. M.; FISCHER, R, G.; FIGUEREDO, C. M.S. Probióticos na Terapia Periodontal. Revista Brasileira Odontologia, v. 69, n. 2, Rio de Janeiro, p. 224-7, Jul/Dez 2012.

BONIFAIT, L.; CHANDAD, F.; GRENIER, D. Probiotics for Oral Health: Myth or Reality. Journal Canadian Dental Association, Otawa, v.75, n. 8, p. 585-590, Oct. 2009.

BRASIL. MINISTÉRIO DA SAÚDE, ANVISA. Lista de Alegações de Propriedade Funcional aprovadas, julho/2008, (item 8 e 9). Disponível em: < http://www.anvisa.gov.br/alimentos/comissões/tecno_lista_alega.htm $>$. Acesso em: 19 de setembro 2019.

COPOLLA, M. M.; TURNES C.G. Probióticos e Resposta Imune. Ciência Rural, v. 34, n. 4, p. 1297 1303, Jul/Ago 2004.

CUPPARI, L. Guia de Nutrição: nutrição Clínica no Adulto. 3.ed. São Paulo: Manole edição, Cap. 5, p. 91-109, 2014.

DENIPOTE, F. G.; TRINDADE, E. B. S. M.; BURINI, R. C. Probióticos e Prebióticos na Atenção Primária ao Câncer de Cólon. Arq. Gastroenterol., v. 47, n. 1, p. 93-98, Jan/Mar 2010.

FOOD INGREDIENTS BRASIL. Probióticos, Prebióticos e Simbióticos. Revista Food Ingredients Brasil. São Paulo, n. 17, p. 58-65, Abr/Mai/Jun 2011. Disponível em: <http://www.revista-fi.com/materiais/177. pdf>. Acesso em: 19 de setembro de 2019.

HUNGRIA, T. D.; LONGO, P. L. Viabilidade de Lactobacillus Casei em Alimento Probiótico Infantil Relacionada a Vida de Prateleira. Revista Saúde, Guarulhos, v. 3, n. 3, p. 10-15, 2009. Disponível em: 
Probióticos e prebiótios na prevenção e...

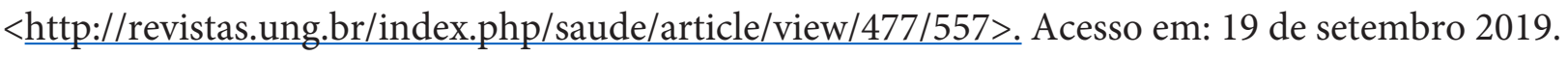

ISOLAURI, E.; SUTTAS, Y.; KANKAANPAA, P.; ARVILOMMI, H.; SALMINEN, S. Probioticos: Efeitos na Imunidade. Revista Americana de Nutrição Clínica, v. 73, p. 444 -450, Edição 2, 1 de fevereiro de 2001.

KOMATSU, T. R.; BURITI, F. C.A.; SAAD, S. M. I. Inovação, Persistência e Criatividade Superando Barreiras no Desenvolvimento de Alimentos Probióticos. Rev. Bras. Cienc. Farm. [online]. v. 44, n. 3 , p. 329-347, Jul/Set 2008.

LAVANDA, I. Prebióticos y su Efecto em La Biodsponibilidad del Cálcio. Revista de Nutrição, Campinas, v. 24, n. 2, p. 333-334, Mar/Apr 2011.

MACEDO, L. N.; LUCHESE, R. H.; GUERRA; A. F.; BARBOSA, C. G. Efeito Prebiótico do Mel sobre o Crescimento e Viabilidade de Bifidobacterium spp. e Lactobacillus spp. em Leite. Ciênc. Tecnol. Aliment. [online]. v.28, n. 4, p. 935-942, Campinas, Oct/Dec 2008.

MAHAN, L; K. STUMP, S; E. Krause Alimentos, Nutrição e Dietoterapia. 12 ed, Rio de Janeiro, Elsevier, cap. 8, p. 255, 2010.

MARTINEZ, R. C. R. Atualidades em Ciências de Alimentos e Nutrição para Profissionais da Saúde. São Paulo, Varela, p. 59-103, 2015.

MELLO, H.; MORAES, J. E.; NIZA, I. G.; MORAES, F.R.; OZÓRIO, R.O.A.; SHIMADA, M. T.; FILHO, J. R. E.; CLAUDIANO, G.S. Efeitos Benéficos de Probióticos no Intestino de Juvenis de Tilápia-doNilo. Pesquisa Veterinária Brasileira, v. 33, n. 6, p. 724-730, Jun 2013.

MORAES, M. B. \& JACOB, C. M. A. O Papel dos Probióticos e Prebióticos na Prática Pediátrica. Jornal de Pediatria, v. 82, n. 5 (Supl), p. 189-197, Nov 2006.

NOGUEIRA, J. C. R.; GONÇALVES, M. C. R. Probióticos. Revista Brasileira de Ciências da Saúde, v. 15, n. 4, p. 487-492, 2011.

PIMENTEL, T. C.; PRUDENCIO, S. H.; RODRIGUES, R. S. Néctar de Pêssego Potencialmente Simbiótico. Alimentos e Nutrição, Araraquara, v. 22, n. 3, p. 455-464, Jul/Set 2011.

ROBERFROID, M. B. Prebióticos e Probióticos: são Alimentos Funcionais? Revista Americana de Nutrição Clínica, v. 71, n. 6, p. 1682S a 1687S, 1 de junho de 2000.

SAAD, S. M. I. Probióticos e Prebióticos: o Estado da Arte. Revista Brasileira de Ciências Farmacêuticas, São Paulo, v. 42, n. 1, p. 1-16, Jan/Mar; 2006.

SAAD, S. M. I.; CRUZ, A. G.; FARIA, J. A. F. Probióticos e Prebióticos em Alimentos: Fundamentos e Aplicações Tecnológicas. São Paulo: Varela, [S.l: s.n.], p. 23-49, 2011.

SETTA, I. C.; FERNANDEZ, A.T. Efeitos dos Probióticos na Prevenção do Tumor de Cólon Intestinal. 
Revista Higiene Alimentar. Científica, São Paulo, v. 24, n. 182, p. 28-34, mar. 2010.

STURMER, E. S.; CASASOLA. S.; GALL, M. C.; GALL, M. C. A Importância dos Probióticos na Microbiota Intestinal Humana. Rev. Bras. Nutr. Clin. n. 27, p. 264-272, Fev 2012.

THAMER, K. G.; PENNA, A. L. B. Efeito do Teor de Soro, Açúcar e de Frutooligossacarídeos sobre a População de Bactérias Lácticas Probióticas em Bebidas Fermentadas. Rev. Bras. Cienc. Farm. [online]. v. 41, n. 3, p. 393-400, Jul/Set 2005.

THAMER, K. G.; PENNA, A. L. B. Caracterização de Bebidas Lácteas Funcionais Fermentadas por Probióticos e Acrescidas de Prebióticos. Ciência e Tecnologia de Alimentos, Campinas, v. 26, n. 3, p. 589-595, Jul/Set 2006.

VARAVAlLO, M. A.; THOMÉ, J. N.; TESHIMA, E. Aplicação de Bactérias Probióticas para Profilaxia e Tratamento de Doenças Gastrointestinais. Semina: Ciências Biológicas e da Saúde, Londrina, v. 29, n. 1, p. 83-104, Jan/Jun2008.

WENDLING, L. K.; WESCHENFELDER, S. Probióticos e Alimentos Lacteis Fermentados. Revista Inst. Laticínios Cândido Tostes, Juiz de Fora, v. 68, n. 395, p. 49-57, Nov/Dez 2013. 